\title{
Burning Sensation
}

National Cancer Institute

\section{Source}

National Cancer Institute. Burning Sensation. NCI Thesaurus. Code C50476.

A sensation of sting ing or heat, not necessarily accompanied by redness or physical signs of irritation. 